\title{
Bradyrhizobium BclA Is a Peptide Transporter Required for Bacterial Differentiation in Symbiosis with Aeschynomene Legumes
}

\author{
Ibtissem Guefrachi, ${ }^{1,2}$ Olivier Pierre, ${ }^{1}$ Tatiana Timchenko, ${ }^{1}$ Benoît Alunni, ${ }^{1}$ Quentin Barrière, ${ }^{1}$ \\ Pierre Czernic, ${ }^{3}$ José-Antonio Villaécija-Aguilar, ${ }^{1}$ Camille Verly, ${ }^{1}$ Mickaël Bourge, ${ }^{1}$ Joël Fardoux, ${ }^{3}$ \\ Mohamed Mars, ${ }^{2}$ Eva Kondorosi, ${ }^{1,4}$ Eric Giraud, ${ }^{3}$ and Peter Mergaert ${ }^{1}$ \\ ${ }^{1}$ Institute for Integrative Biology of the Cell, UMR 9198, CNRS/Université Paris-Sud/CEA, Gif-sur-Yvette, France; ${ }^{2}$ Research \\ Unit Biodiversity \& Valorization of Arid Areas Bioressources (BVBAA), Faculty of Sciences, Gabès, Tunisia; ${ }^{3}$ Laboratoire \\ des Symbioses Tropicales et Méditerranéennes, Institut pour la Recherche et le Développement, UMR IRD/SupAgro/ \\ INRA/UM2/CIRAD, Montpellier, France; ${ }^{4}$ Institute of Biochemistry, Hungarian Academy of Sciences, Biological \\ Research Centre, Szeged, Hungary
}

Submitted 15 April 2015. Accepted 14 June 2015.

\begin{abstract}
Nodules of legume plants are highly integrated symbiotic systems shaped by millions of years of evolution. They harbor nitrogen-fixing rhizobium bacteria called bacteroids. Several legume species produce peptides called nodule-specific cysteine-rich (NCR) peptides in the symbiotic nodule cells which house the bacteroids. NCR peptides are related to antimicrobial peptides of innate immunity. They induce the endosymbionts into a differentiated, enlarged, and polyploid state. The bacterial symbionts, on their side, evolved functions for the response to the NCR peptides. Here, we identified the $b c l A$ gene of Bradyrhizobium sp. strains ORS278 and ORS285, which is required for the formation of differentiated and functional bacteroids in the nodules of the NCR peptide-producing Aeschynomene legumes. The BclA ABC transporter promotes the import of NCR peptides and provides protection against the antimicrobial activity of these peptides. Moreover, BclA can complement the role of the related BacA transporter of Sinorhizobium meliloti, which has a similar symbiotic function in the interaction with Medicago legumes.
\end{abstract}

An evolutionary strategy, frequently used by certain groups of organisms such as insects or plants to solve the lack of specific nutrients in their food, is the establishment of symbiotic interactions with microorganisms that are able to produce those nutrients (Moran 2006). A well-known example, studied intensively for its agronomic and ecological impact, is the interaction of legumes with nitrogen-fixing bacteria. Bioavailable nitrogen is limiting to plant growth, yet legumes have the capacity to thrive on nitrogen-poor soils thanks to the

Present address of J.-A. Villaécija-Aguilar: Institute of Genetics, University of Munich (LMU), Martinsried, Germany.

Present address of C. Verly: Institut Jean-Pierre Bourgin, Versailles, France.

Corresponding author: P. Mergaert; Telephone: +33 1698237 90;

E-mail: peter.mergaert@i2bc.paris-saclay.fr

*The $\boldsymbol{e}$-Xtra logo stands for "electronic extra" and indicates that eight supplementary figures and two supplementary tables are published online.

(c) 2015 The American Phytopathological Society reduction of airborne nitrogen gas to ammonia by their symbiotic partners. These legume symbiotic bacteria, commonly called rhizobia, are phylogenetically disparate $\alpha$ - and $\beta$-proteobacteria belonging to the orders Rhizobiales and Burkholderiales, respectively (Masson-Boivin et al. 2009).

As in other nutritional symbioses, fulfilling all the nutritional needs of the host plant by the endosymbiotic rhizobia requires the hosting of millions to billions of them. To achieve this challenging task, legumes form specific organs called nodules on their roots and, in certain species, also on their stems. Nodules, in large part, are composed of specialized symbiotic cells which are giant polyploid cells, each carrying several hundreds to thousands of intracellular rhizobia (Kondorosi et al. 2013). This particularly high bacterial load requires the establishment of homeostasis between the two symbionts, whereby immunity responses of the symbiotic cells do not eliminate the microsymbionts and, inversely, the massive colonization of the host cells does not result in their collapse. A modus operandi to maintain the endosymbiotic rhizobial population under control, described in IRLC and Dalbergoid legumes, is enforcing the intracellular bacteria into a terminal differentiation process which is characterized by cell enlargement, polyploidy, and incapacity of the bacteria to reproduce. Bacteroids in this type of legume are elongated (E-morphotype) or spherical (S-morphotype) (Kondorosi et al. 2013; Mergaert et al. 2006). However, in other legumes, this terminal differentiation does not exist. They carry in their nodules unmodified (U-morphotype) bacteroids (Kondorosi et al. 2013; Mergaert et al. 2006). The ancestral state of the bacteroids is considered to be of the Umorphotype and the other morphotypes have appeared later in evolution (Oono et al. 2010). Because IRLC and Dalbergoids are distantly related legume clades, it is inferred that the molecular mechanisms for bacteroid differentiation have evolved independently in these clades.

In the Sinorhizobium meliloti-Medicago spp. (IRLC legumes) symbiosis, the formation of the E-morphotype bacteroids is under the control of a particular class of peptides called the nodule-specific cysteine-rich (NCR) peptides, which are massively produced by the symbiotic cells and targeted by the secretory pathway to the endosymbionts, inducing them in the polyploid differentiated state (Van de Velde et al. 2010). The polyploidy of the bacteroids implies an interference of the peptides with the bacterial cell cycle, such that division is 
inhibited while DNA replication continues. This is achieved, at least in part, by targeting the bacterial cell cycle regulator CtrA (Penterman et al. 2014; Pini et al. 2013). NCR peptides are conserved in all tested E-morphotype-forming IRLC legumes but other legumes forming U-morphotype bacteroids, such as, for example, Lotus japonicus, Phaseolus vulgaris (bean), or Glycine max (soybean), lack NCR genes, explaining why bacteroids in those legumes remain unmodified (Kondorosi et al. 2013).

NCR peptides are similar to antimicrobial peptides and have in vitro antimicrobial activity (Haag et al. 2011; Van de Velde et al. 2010). The BacA transporter protein of $S$. meliloti provides protection against this antimicrobial activity and is required for the persistence of $S$. meliloti in the NCR-producing symbiotic cells of Medicago nodules. A bacA mutant does not differentiate in these symbiotic cells but dies off very rapidly after its release and exposure to the NCR peptides inside the symbiotic cells due to its hypersensitivity to these peptides (Glazebrook et al. 1993; Haag et al. 2011).

Legumes of the genus Aeschynomene belong to the Dalbergoid clade and form either E- or S-morphotype bacteroids, depending on the species (Bonaldi et al. 2011; Czernic et al. 2015). We have shown recently that Aeschynomene afraspera nodules housing E-morphotype bacteroids or A. indica and $A$. evenia nodules housing S-morphotype bacteroids produce NCR peptides. However, these Aeschynomene NCR peptides have no sequence homology to the NCR peptides of IRLC legumes and, therefore, are of an independent evolutionary origin (Czernic et al. 2015). These peptides, which are specifically produced by the symbiotic cells and targeted to the bacteroids, are most likely involved in the formation of the differentiated bacteroids. Thus, despite the independent evolution of the bacterial differentiation, similar mechanisms seem to operate in the IRLC and Dalbergoid legume clades. To further corroborate this notion, we identified in the present study bclA, a bacA-like gene, in the Bradyrhizobium spp. that nodulate Aeschynomene plants and demonstrate its role in bacteroid differentiation in those plants.

BacA of S. meliloti and SbmA, a homolog in Escherichia coli, are transporters composed solely of an SbmA_BacA transmembrane domain (LeVier and Walker 2001). They have the notable feature of internalizing a variety of structurally diverse peptides, including the antibiotic bleomycin and the mammalian peptide Bac7 (Ghosal et al. 2013; Marlow et al. 2009; Mattiuzzo et al. 2007; Narayanan et al. 2014; Puckett et al. 2012; Wehmeier et al. 2010; Yorgey et al. 1994). The uptake of these antimicrobial compounds by the SbmA/BacA "multidrug" transporter alters the sensitivity of the bacteria toward these molecules. Here, we find that the Bradyrhizobium BclA protein increases sensitivity toward bleomycin and Bac7, suggesting that it is a transporter of these molecules. Moreover, we show that BclA, as well as $S$. meliloti BacA, are able to import NCR peptides.

\section{RESULTS}

\section{Symbiotic role of the Bradyrhizobium SbmA_BacA domain transporters.}

The genomes of analyzed Bradyrhizobium spp. (Bradyrhizobium sp. strains ORS285, ORS278, and BTAi1 and Bradyrhizobium japonicum USDA110), including the symbionts of Aeschynomene spp. carry three genes encoding proteins weakly homologous (21 to $25 \%$ amino acid identity) to BacA of $S$. meliloti, characterized by the presence of the transmembrane domain pfam06472 (ABC_membrane_2) or pfam05992 (SbmA_BacA). A phylogenetic tree of SbmA_BacA domain proteins did not reveal a close alliance to the BacA protein for any of these three proteins (Fig. 1).
To determine whether the Bradyrhizobium genes have a symbiotic role, we constructed mutants in the three genes of strain ORS285 (BRAO285v1_1320006, BRAO285v1_250005, and BRAO285v1_950010) which can nodulate diverse Aeschynomene spp. housing either S- or E-morphotype bacteroids (Bonaldi et al. 2011). Only the mutant in gene BRAO285v1_1320006 had a symbiotic phenotype on the host plants $A$. indica and A. afraspera. It formed nodules which looked aberrant in size, form, and color. These nodules had a strongly reduced nitrogen fixation activity (approximately 5 and $20 \%$ of wild-type levels in A. indica and A. afraspera, respectively) and could not fully support plant growth in nitrogen-poor growth conditions, as was obvious from the leaves showing chlorosis and the reduced plant shoot mass (Fig. 2 ). The mutants in the other two genes, on the other hand, formed normal nitrogen-fixing nodules, indicating that these genes are not required for symbiosis (Fig. 2). Interestingly, in a screen of a collection of Tn5 transposon mutants of $\mathrm{Bra}$ dyrhizobium sp. strain ORS278, we previously identified a mutant in the gene BRADO6119, orthologous to the ORS285 gene BRAO285v1_1320006, which formed nonfunctional nodules on A. indica (Bonaldi et al. 2010b). We found that the mutations in these genes in both strains were not affecting freeliving nitrogen fixation or bacterial growth (Supplementary Fig. S1), indicating that the symbiotic phenotype of the mutants does not result from a defect in the nitrogen fixation metabolism or a general growth defect.

These observations together, with their further characterization described below, indicate that the genes BRAO285v1_1320006 and BRADO6119 encode BacA-like proteins. However, the Bradyrhizobium proteins differ from BacA or the E. coli homolog SbmA by the presence of a C-terminal cytosolic ATPase domain typical for canonical ABC transporters (Fig. 1). Therefore, we named them $b c l A$, for "Bradyrhizobium bacA-like".

\section{Bradyrhizobium BclA is required}

\section{for polyploid bacteroid differentiation.}

In order to identify the specific defect in the A. afraspera and $A$. indica nodules infected with the ORS285 $\Delta b c l A$ mutant, we analyzed the histology of these nodules by light and confocal microscopy and compared it with wild-type infected nodules. Thin sections of resin-embedded nodules were stained with toluidine blue and observed by light microscopy (Fig. 3). The diameter of the nodules infected with the mutant strain was markedly smaller than for the nodules infected with the wildtype strain, particularly for the $A$. indica nodules; however, their central tissue was fully occupied with symbiotic cells and the surrounding cortical cell layers were normally formed (Fig. 3A to D). The cytosolic space of the symbiotic cells was completely filled with rhizobia, similarly to symbiotic cells in wildtype nodules (Fig. 3E to H). However, in both $A$. afraspera and A. indica, the morphology of the bacteroids was aberrant, whereas in nodules of these two plants infected with wildtype ORS285, the bacteroids were strongly elongated (Emorphotype) or spherical (S-morphotype), respectively, in nodules infected with the mutant, the bacteroids in both plant species remained small, very similar to undifferentiated bacteria (Fig. 3E to H). The live-dead staining of nodule sections to analyze the persistence of the $b c l A$ mutant bacteria within the symbiotic cells revealed that, despite this undifferentiated state, the bacteria remained viable in A. afraspera nodules, as indicated by the green Syto9 staining, until at least 14 days after inoculation (Fig. 3F). In contrast, in $A$. indica nodules, the viability of the mutant was more strongly affected and, at 14 days postinoculation, many bacteria were dead, as indicated by their red staining due to propidium iodide (PI) uptake (Fig. 3H). The degradation of the symbiotic cells and their 
bacteroids in A. indica nodules could also be seen on the resinembedded nodule sections. To further explain the strongly reduced nitrogen fixation ability of the bacteroids in A. afraspera nodules, we used the acidophilic DND-99 LysoTracker probe which marks actively fixing bacteroids by red fluorescence due to acidification of the peribacteroid space. The acidification of the peribacteroid space is due, in part, to the metabolic activity of the residing bacteroid (Pierre et al. 2013). We found that, in the $A$. afraspera nodules, the $b c l A$ mutant bacteroids were not stained by DND-99 in many symbiotic cells (Supplementary Fig. S3). Thus, although the mutant bacteroids in A. afraspera nodules are viable and have intact membranes, as indicated by the absence of PI staining, their activity is affected by the absence of BclA function.

The nondifferentiated state of the bacteroids formed by the mutant strain was further verified and quantified precisely. Bacteroids were isolated from nodules and purified on a density gradient, then analyzed by flow cytometry. The forward scatter
(FS) of the bacteria is relative to their size. The bacteroids isolated from A. afraspera and A. indica nodules had a higher FS than the cultured ORS285 bacteria (Fig. 3I and K), in agreement with their enlarged size. The $b c l A$ mutant bacteroids, on the other hand, had an FS that was intermediate between the FS of cultured bacteria and wild-type bacteroids, supporting their differentiation defect observed by microscopy. The bacteroids in A. afraspera and A. indica nodules have a high DNA content (Czernic et al. 2015). Therefore, we also measured the DNA content of the $b c l A$ mutant bacteroids, isolated from $A$. afraspera and $A$. indica nodules and stained with the DNA fluorescent stain 4',6-diamidino-2phenylindole (DAPI). The mean DNA content of the wild-type bacteroids was 7 genome complements (7C) and $16 \mathrm{C}$ in A. afraspera and $A$. indica, respectively, whereas the mutant bacteroids reached only 1 to $3 \mathrm{C}$ ploidy levels, close to the $1 \mathrm{C}$ to $2 \mathrm{C}$ ploidy of free-growing Bradyrhizobium sp. strain ORS285 bacteria (Fig. 3J and L), confirming the nearly

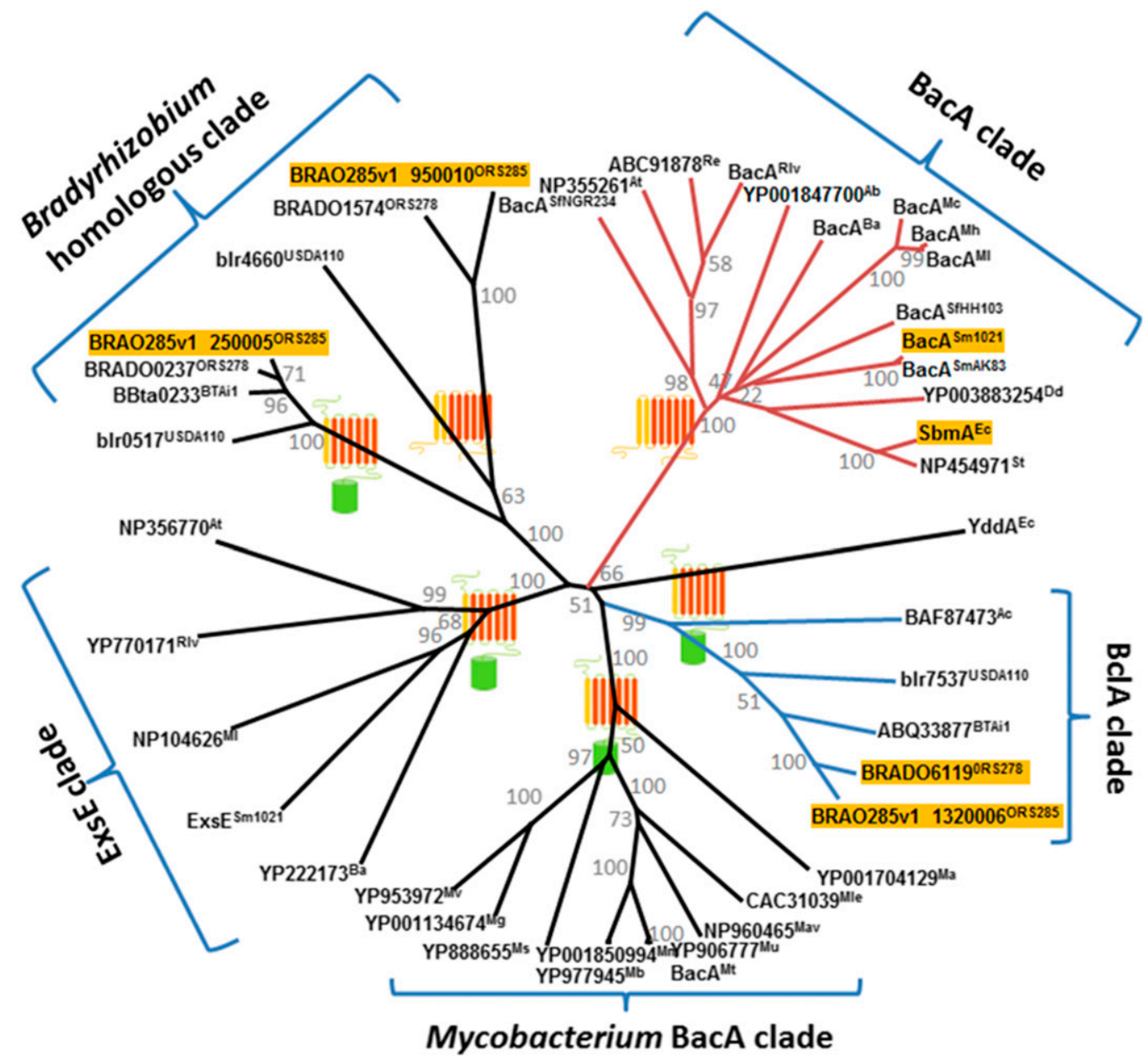

Fig. 1. Phylogenetic tree of SbmA_BacA domain proteins. The neighbor-joining tree was generated from a ClustalW2 alignment. Protein sequences used for the alignment and tree generation are provided in Supplementary Table S1. All identified SbmA_BacA domain proteins of the included bacterial species are represented. Percentage of bootstrap replicates (500 replicates) are indicated at each tree node. Bacterial species origin of the proteins are indicated with a suffix: Ab, Acinetobacter baumanii; Ac, Azorhizobium caulinodans; At, Agrobacterium tumefaciens; ORS278, Bradyrhizobium sp. strain ORS278; ORS285, Bradyrhizobium sp. strain ORS285; BTAi1, Bradyrhizobium sp. strain BTAi1; USDA110, Bradyrhizobium japonicum USDA110; Ba, Brucella abortus; Dd, Dickeya dadantii; Ec, Escherichia coli; Ma, Mycobacterium abscessus; Mav, M. avium; Mb, M. bovis; Mc, Mesorhizobium ciceri; Mg, M. gilvum; Mh, M. huakuii; Ml, M. loti; Mle, M. leprae; Mm, M. marinum; Ms, M. smegmatis; Mt, M. tuberculosis; Mu, M. ulcerans; Mv, M. vanbaalenii; Re, Rhizobium etli; Rlv, Rhizobium leguminosarum bv. viciae; SfHH103, Sinorhizobium fredii strain HH103; SfNGR234, S. fredii strain NGR234; Sm1021, S. meliloti strain Sm1021; SmAK83, S. meliloti strain AK83; St, Salmonella typhimurium. Proteins discussed in this study are highlighted in orange. Branches carrying transporters involved in symbiosis are colored red (BacA branch) or blue (BclA branch). All other Bradyrhizobium SbmA_BacA domain transporters are in the Bradyrhizobium homologous clade. Mycobacterium homologs form the separate Mycobacterium BacA clade. The ExsE clade is named after the S. meliloti ExsE protein. Domain structures of the proteins are illustrated schematically behind the tree branches. Transmembrane helices of the SbmA_BacA domain are colored red. Additional transmembrane helices are in yellow. The ATPase domain (green) is only present in some branches. Proteins of the BacA clade lack the ATPase domain while BclA clade proteins have an ATPase domain and are ABC transporters. 

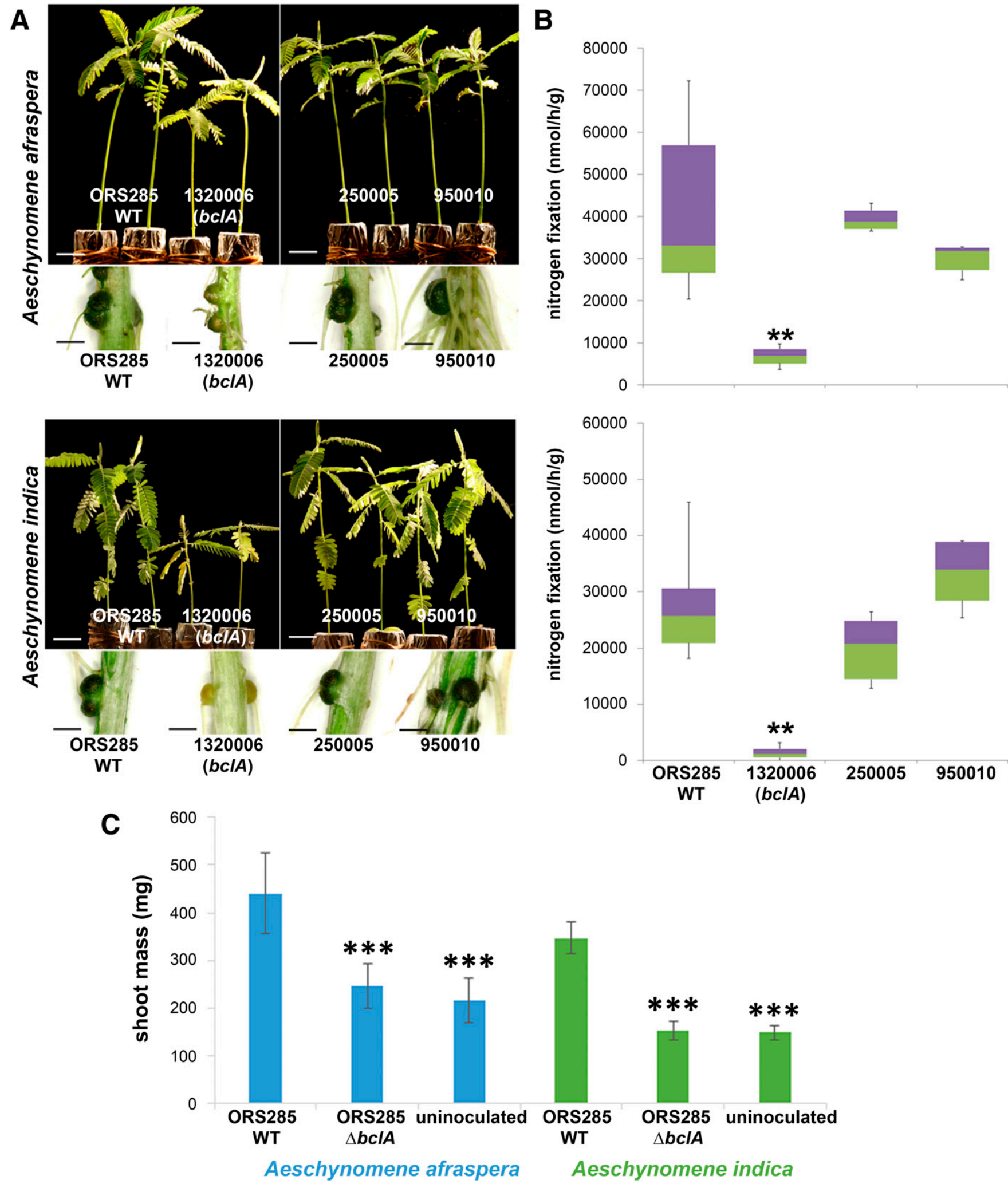

\section{Aeschynomene indica}

Fig. 2. Symbiotic phenotype of Bradyrhizobium sp. strain ORS285 mutants in SbmA_BacA domain-containing proteins. A, Plant growth and nodule phenotype at 14 days postinoculation (dpi) of Aeschynomene afraspera (top panel) and A. indica (bottom panel) plants inoculated with the ORS285 wild type (WT) and its mutant derivatives in the BRAO285v1_1320006 (bclA), BRAO285v1_250005, and BRAO285v1_950010 genes. Scale bars = $2 \mathrm{~cm}$ and $2.5 \mathrm{~mm}$, respectively. B, Nitrogen fixation activity at $14 \mathrm{dpi}$ of $A$. afraspera (top panel) and $A$. indica (bottom panel) plants inoculated with the indicated strains, measured by the acetylene reduction assay per gram of fresh nodule weight (nanomoles of ethylene produced per hour of incubation and per gram nodule weight). In the rectangle, box plots represent the first quartile to the third quartile, divided by the median value; whiskers above and below the box show the minimum and maximum measured values, respectively. Statistical analysis was made with a Mann-Whitney $U$ test $(n=5$; ** indicates $P<0.001)$. C, Fresh weight shoot mass of A. afraspera and A. indica plants at $14 \mathrm{dpi}$ inoculated with ORS285 or ORS285 $\Delta b c l A$ or uninoculated. The experiment was carried out in duplicate with 10 plants per condition. Error bars represent standard deviation and significance was determined by the Kruskal and Wallis test $(* * *$ indicates $P<0.0001)$. 
undifferentiated state of the bacteroids formed by the $b c l A$ mutant observed by microscopy.

To assert that the described phenotypes were linked to the deletion of the $b c l A$ gene in strain ORS285, we also analyzed the phenotype of the $b c l A$ Tn5 insertion mutant in strain ORS278 (Bonaldi et al. 2010b). Nodulation of A. indica and A. evenia with this mutant could not support the growth of these plants in the absence of external nitrogen; the nodules were abnormally formed, indicative that they were nonfunctional; bacteroids did not become spherical but remained similar in morphology to free-living rhizobia; and these bacteroids were PI positive (Supplementary Fig. S4). Moreover, reintroducing the wild-type $b c l A$ gene on a plasmid in the ORS285 $\Delta b c l A$ mutant restored the bacteroid differentiation defects to wildtype levels (Fig. 4) and, by consequence, also their nitrogen fixation activity (Supplementary Fig. S5).

\section{Bradyrhizobium BclA is functionally equivalent} to $S$. meliloti BacA in symbiosis.

Because the phenotype of the Bradyrhizobium bclA mutants is reminiscent of the $S$. meliloti bacA mutant phenotype, we wanted to determine whether $b a c A$ and $b c l A$ are interchangeable for their symbiotic function. Introducing the $S$. meliloti $b a c A$ gene on a plasmid in strain ORS285 $\Delta b c l A$ did not improve its bacteroid differentiation and nitrogen fixation defect (Fig. 4), suggesting that BacA protein lacking the ATPase domain is not sufficient to replace the $\mathrm{BclA} A B C$ transporter. Therefore, we investigated the capacity of the $b c l A$ gene of Bradyrhizobium sp. strain ORS285 to complement the symbiotic defect of an S. meliloti bacA deletion mutant infecting Medicago sativa nodules. This mutant forms nodules on Medicago plants in which symbiotic cells are filled with nondifferentiated, dead bacteria because the bacA mutant cells are hypersensitive to the antimicrobial action of certain NCR peptides produced by these symbiotic cells (Haag et al. 2011). The phenotype of the mutant could be easily scored by the aspect of the nodules which were small and white compared with the large, elongated, and pink wild-type nodules (Fig. 5A to $\mathrm{C})$. This pink color results from the abundant production of leghemoglobin in the cytosol of symbiotic cells during the late stages of their formation, just before the onset of nitrogen fixation. Also, live-dead staining of nodule sections and observation by confocal microscopy easily revealed the mutant phenotype: in nodules infected with the bacA mutant, the symbiotic cells contained dead bacteria, stained red by PI, and only the infection threads carried live bacteria, stained green by Syto9; whereas, in nodules infected with the wild-type strain, symbiotic cells were entirely occupied with live bacteria, which were stained green by Syto9 (Fig. 5E to G and I to K). The absence of differentiation of the bacteroids in the mutant could also be measured by flow cytometry analysis of bacteria extracted from nodules because the mutant bacteria did not

\section{Aeschynomene afraspera}
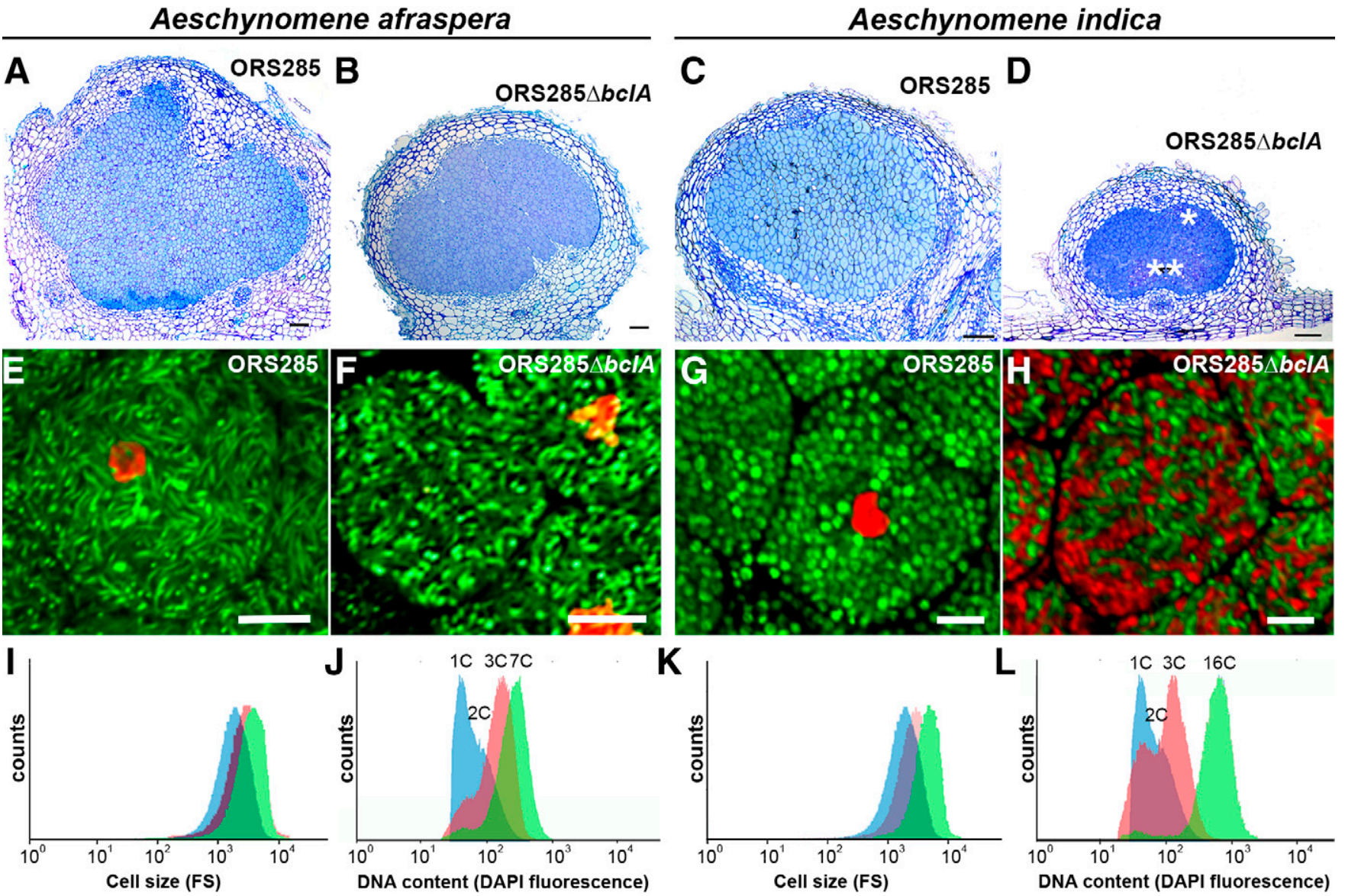

Fig. 3. Small nodule size and abnormal bacteroids of ORS285 $\Delta$ bclA in Aeschynomene afraspera and $A$. indica. A to D, Toluidine blue-stained thin sections, 14 days postinoculation (dpi), of $A$. afraspera and A. indica nodules induced by ORS285 or ORS285 $\Delta b c l A$. Scale bars $=100 \mu \mathrm{m}$. Zones in D indicated by an asterisk and double asterisk are shown enlarged in Supplementary Figure S2. E to H, Bacteroid viability determined by live-dead staining of nodule sections and confocal microscopy in A. afraspera and A. indica nodules induced by ORS285 or ORS285 $\Delta b c l A$. Scale bars $=10 \mu \mathrm{m}$. I to $\mathbf{L}$, Flow cytometry analysis of bacteroid size and DNA content. Forward scatter (FS) (I and K) and 4',6-diamidino-2-phenylindole (DAPI) fluorescence (J and L) in free-living Bradyrhizobium sp. strain ORS285 bacteria (blue) or bacteroids isolated from A. afraspera (I and J) or A. indica (K and $\mathrm{L}$ ) nodules infected with ORS285 wild type (green) or ORS285 $\Delta b c l A$ (red). 
amplify their genome, in contrast to the wild-type strain (Fig. $5 \mathrm{M}$ to $\mathrm{O}$ ). The $S$. meliloti bacA mutant strain carrying the bclA gene of ORS285 induced the formation of nodules which were elongated, although not to the same level as the same strain carrying the $b a c A$ gene, and those nodules were slightly pinkish, indicating that the leghemoglobin production was partially restored (Fig. 5C and D). Nevertheless, those nodules were not fixing nitrogen (data not shown). The confocal microscopy of live-dead stained nodule sections showed that the bacteroids of the $b c l A$-expressing strain were elongated and mostly stained green although, in older symbiotic cells, many dead bacteria were also detected which were nevertheless elongated (Fig. $5 \mathrm{H}$ and L). Flow cytometry analysis of the DNA content in nodule bacteria also showed that the presence of the $b c l A$ gene restored the polyploidization of the bacteroids to similar levels as in the strain carrying the $b a c A$ gene or the wild-type strain (Fig. 5M to $\mathrm{P})$. Thus, all together, these results indicated that the $b c l A$ gene could complement the endogenous bacA gene, although this complementation was only partial and insufficient to restore the nitrogen fixation capacity of the strain.

\section{Bradyrhizobium BclA has multidrug transport activity.}

Different peptide-derived antibiotic compounds have been shown to be taken up by bacterial cells in an SbmA- or BacAdependent manner. Among them is bleomycin, which is a DNA-damaging antibiotic. In both $E$. coli and $S$. meliloti, the resistance to bleomycin is increased by mutations in $s b m A$ and bacA, respectively (Ichige and Walker 1997; Wehmeier et al. 2010). We observed that the bclA mutants of Bradyrhizobium sp. strains ORS278 and ORS285 were more resistant to bleomycin than their parent wild-type strains (Fig. 6A). Also, the introduction of the $b c l A$ gene on a plasmid into the ORS285 bclA mutant strongly enhanced its sensitivity to bleomycin (Fig. 6A). Moreover, the ORS285 bclA gene conferred sensitivity to bleomycin in an E. coli sbmA mutant or in an S. meliloti bacA mutant (Supplementary Fig. S6), indicating that BclA can mediate the import of bleomycin in heterologous bacteria. In contrast, the introduction of the $b a c A$ gene on a plasmid into the ORS285 bclA mutant did not restore bleomycin sensitivity (Fig. $6 \mathrm{~A})$, confirming that the BacA protein was not sufficient to replace the $\mathrm{BclA} \mathrm{ABC}$ transporter in Bradyrhizobium spp. This result is in agreement with the inability of the $b a c A$ gene to complement the symbiotic defect of the $b c l A$ mutant (Fig. 4).

Bac7 is a mammalian proline-rich cathelicidin-type of antimicrobial peptide with an intracellular mode of action, binding ribosomes and thereby inhibiting the translation process (Mardirossian et al. 2014). The uptake of the Bac7 peptide is dependent on the SbmA or BacA transporter in E. coli or S. meliloti, respectively (Marlow et al. 2009; Mattiuzzo et al. 2007). Therefore, we wondered whether the BclA protein can also import the Bac7 peptide into bacterial cells. The Bac7 peptide has no antimicrobial activity in the tested concentration range, up to $4 \mu \mathrm{M}$, on the Bradyrhizobium spp. strains used in this study. Bradyrhizobium bacteria could be resistant to Bac7 if the ribosome target it binds to in E. coli or $S$. meliloti has diverged in sequence in Bradyrhizobium spp. Therefore, we tested the effect of the BclA protein in E. coli or $S$. meliloti. The expression of the bclA gene of strains ORS285 in the E. coli sbmA or $S$. meliloti bacA mutants rendered them more sensitive to the Bac7 peptide, in agreement with the $\mathrm{BclA}$ protein also being able to internalize the Bac7 peptide (Supplementary Fig. S7).

S. meliloti BacA enhances the resistance of the bacterium toward NCR peptides produced by the symbiotic cells in Medicago nodules (Haag et al. 2011). We analyzed how the BclA transporter affects the bacterial sensitivity to NCR peptides. Unfortunately, none of the currently tested Aeschynomene NCR peptides nor any of the Medicago NCR peptides had antimicrobial activity on Bradyrhizobium bacteria or their bclA mutants (Czernic et al. 2015). Therefore, we assayed the BclA proteins in the $S$. meliloti background as above for the Bac7 peptide. The $S$. meliloti $\triangle$ bacA mutant is highly sensitive to three tested NCR peptides (NCR247, NCR335, and NCR035) and this sensitivity is strongly reduced when the $b c l A$ gene of Bradyrhizobium sp. strain ORS285 was introduced on a plasmid (Fig. 6B). Similarly, the $s b m A$ gene of $E$. coli and the bacA gene itself enhanced the resistance of the bacA mutant. In addition, one tested $A$. afraspera NCR peptide, AaNCR01, displayed a moderate antimicrobial activity against the $S$. meliloti $\triangle b a c A$ mutant, which was reduced by plasmid-born bacA or $b c l A$. Taken together, these results suggest that all three tested transmembrane transporters (BclA, SmbA, and BacA) are able
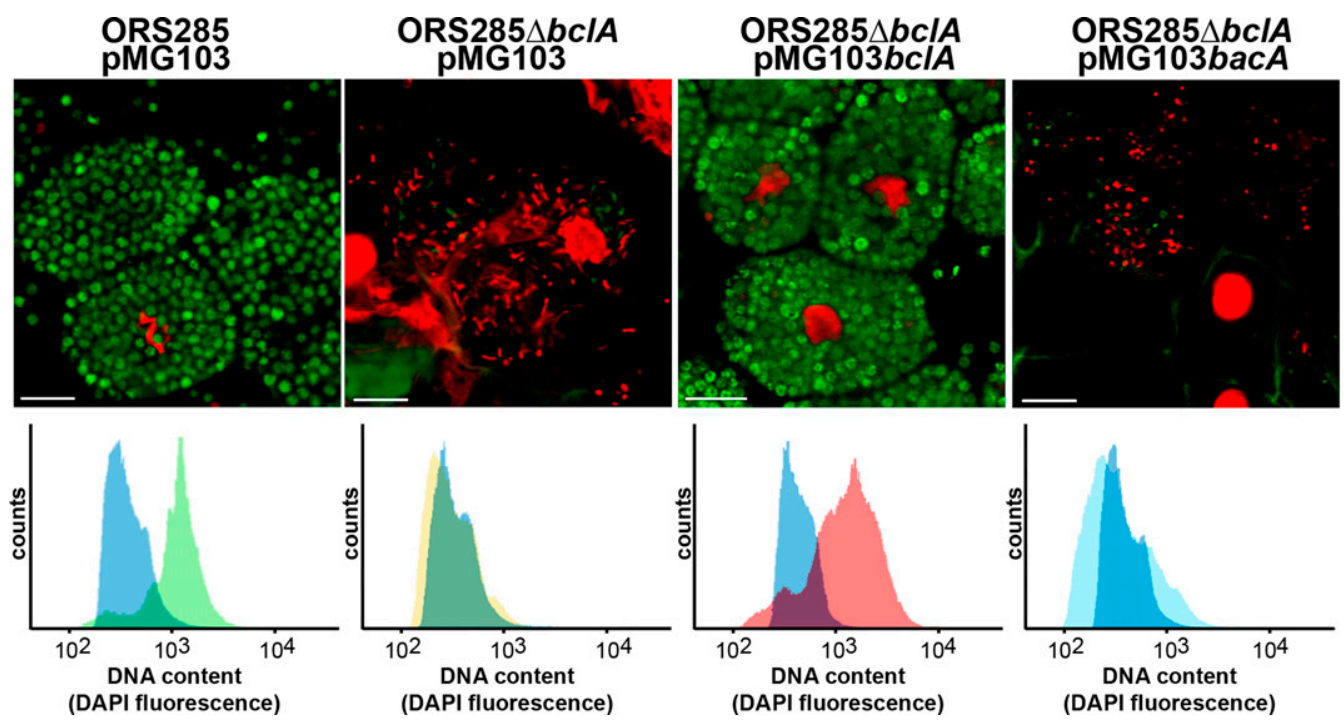

Fig. 4. Complementation of the bacteroid differentiation phenotype of ORS285 $\Delta b c l A$ by the $b c l A$ or $b a c A$ genes. Top panels: confocal microscopy 14 days postinoculation of live-dead-stained sections of Aeschynomene indica nodules infected with the indicated strains. Bottom panels: Flow cytometry analysis of the DNA content in 4',6-diamidino-2-phenylindole (DAPI)-stained bacteroids purified from A. indica nodules infected with the indicated strains. Blue histograms are from cultured ORS285 bacteria and the overlays in green, yellow, red, or light blue are the bacteroid measurements. Scale bars $=10 \mu \mathrm{m}$. 
to provide protection against the activity of the tested Medicago and Aeschynomene NCR peptides (Fig. 6B).

The SbmA and BacA transporters modulate the bacterial susceptibility to bleomycin and Bac7 by promoting the uptake of these peptides (Mardirossian et al. 2014; Marlow et al. 2009; Mattiuzzo et al. 2007; Wehmeier et al. 2010). Whether the NCR peptides are also taken up by the BacA, SbmA, or BclA transporters is unknown. We used a fluorescent derivative of the NCR247 peptide, carrying at its N-terminus a fluorescein isothiocyanate (FITC) modification. FITC-NCR247 had been shown to be taken up by free bacteria and bacteroids (Farkas et al. 2014). We used flow cytometry to measure the uptake of FITC-NCR247 by the S. meliloti strain Sm1021 or by Sm1021 $\triangle$ bacA derivatives expressing from a plasmid-born copy the $b a c A$ or $b c l A$ gene or no gene (Fig. 7A). The mutant without any transporter was unable to take up the peptide under the applied conditions whereas the wild-type strain or the mutant strains expressing one of the tested genes were able to transport the fluorescent peptide, as revealed by the appearance of a fluorescent bacterial population. Fluorescence microscopy of sorted FITC-positive bacteria confirmed that these bacteria had taken up the NCR peptide, which appeared in the cells as discrete foci (Fig. 7B). In this assay, only a fraction of the bacteria were FITC positive. The reason for this is presently not understood and requires further analysis. Possibly the NCR peptide or its FITC moiety was not stable in the cells, or FITC fluorescence was quenched and only a portion of the cells maintained sufficient FITC to be detected in the assay.

In a control experiment, we used FITC alone in the assay, and this compound was unable to label the cells (Supplementary Fig. S8), demonstrating that the uptake of fluorescence is NCR247 dependent. Together, our experiments show that the BclA protein mediates resistance to NCR peptides in a manner similar to BacA and, possibly, this resistance mechanism involves the uptake of the peptides by the BclA or BacA transporter proteins.

\section{DISCUSSION}

Since its initial description in $M$. truncatula (Mergaert et al. 2003), the use of cysteine-rich peptides or other types of antimicrobial peptides in the management of large endosymbiotic bacterial populations has now been found in several other symbiotic interactions, including in other nitrogen-fixing interactions of actinorhizal plants with gram-positive Frankia bacteria (Carro et al. 2015; Demina et al. 2013; Hocher et al. 2011), but also in interactions of several groups of insects with

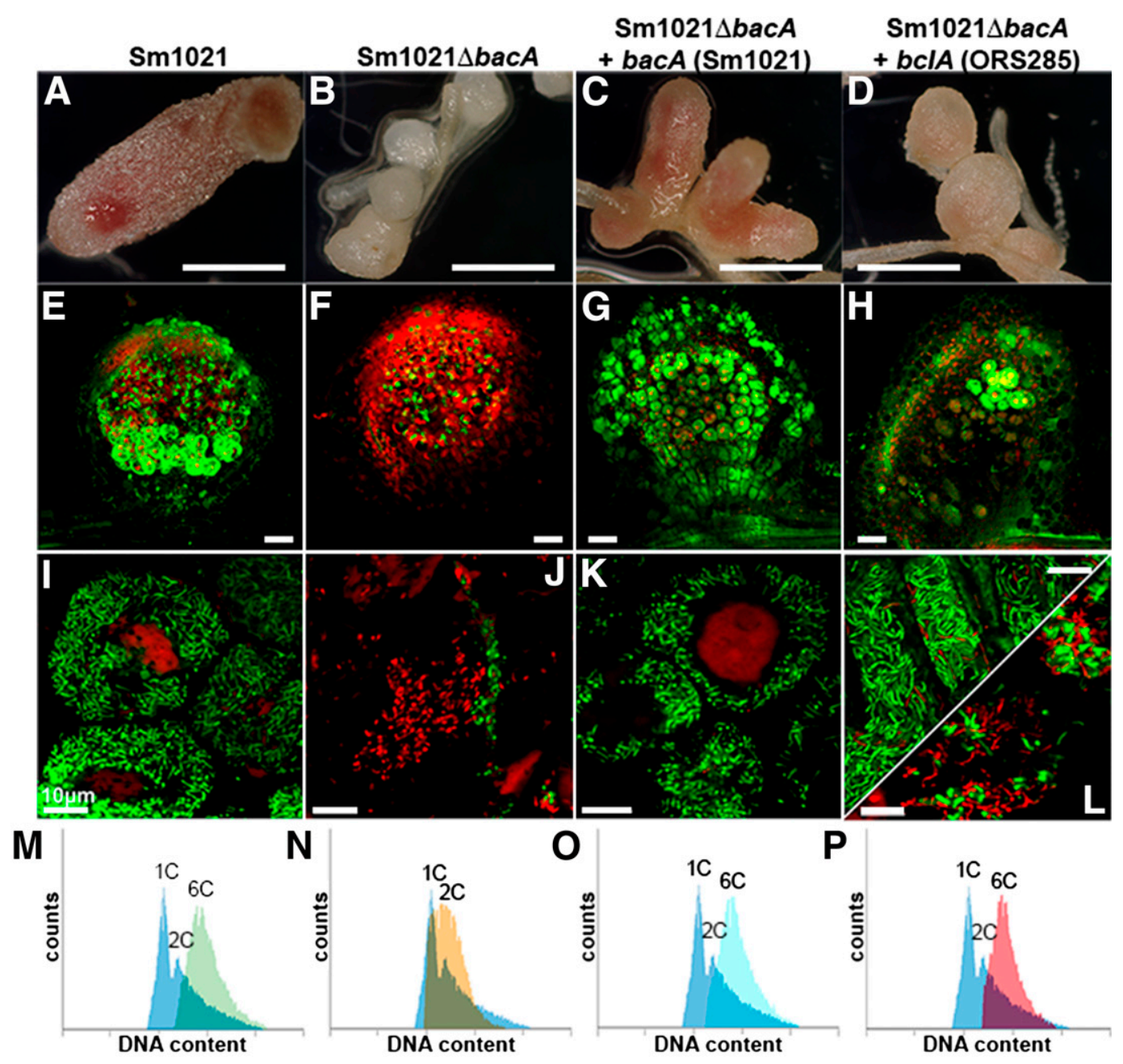

Fig. 5. Complementation of the Sinorhizobium meliloti bacA mutation with Bradyrhizobium sp. strain ORS285 bclA. A to D, Phenotype of Medicago sativa nodules at 28 days postinoculation infected with the indicated strains. Scale bars $=1 \mathrm{~mm}$. $\mathbf{E}$ to $\mathbf{L}$, Bacteroid viability determined by live-dead staining of nodule sections and confocal microscopy in $M$. sativa nodules induced by the indicated strains. Scale bars $=100 \mu \mathrm{m}(\mathrm{E}$ to $\mathrm{H})$ or $10 \mu \mathrm{m}$ (I to L). $\mathbf{M}$ to $\mathbf{P}$, Flow cytometry analysis of the DNA content by 4',6-diamidino-2-phenylindole fluorescence in free-living $S$. meliloti (blue in all panels) or bacteroids isolated from $M$. sativa nodules infected with the $S$. meliloti wild type (M, green), the $S$. meliloti bacA mutant (N, orange), the $S$. meliloti bacA mutant complemented with the $S$. meliloti bacA gene (O, pale blue), or the $S$. meliloti bacA mutant complemented with the ORS285 bclA gene (P, red). 
endosymbiotic bacteria (Futahashi et al. 2013; Login et al. 2011; Shigenobu and Stern 2012). Even the microbiota in the gut from the most basal animals to the mammals are kept in homeostasis by antimicrobial peptides produced by host epithelial cells (Fraune et al. 2010; Ryu et al. 2008; Salzman et al. 2010). We recently reported the production of NCR peptides in the symbiotic nodule cells of legume species belonging to the genus Aeschynomene and that their bacteroids have features (strong cell enlargement, polyploidy, membrane permeabilization, and loss of cell viability) similar to those found in Medicago spp. and other IRLC legumes (Czernic et al. 2015). These observations suggest that the distantly related IRLC and Dalbergoid legumes have converged independently toward the same strategy: controlling their endosymbionts by forcing them into an irreversible, differentiated state and using cysteine-rich peptides for this. In the present study, we show that this convergent evolution extends also to the endosymbionts' use of BacA_SbmA domain transporters to be able to respond to the NCR peptides produced by the host cells and to differentiate into functional bacteroids. We showed before that BacA is required for $S$. meliloti
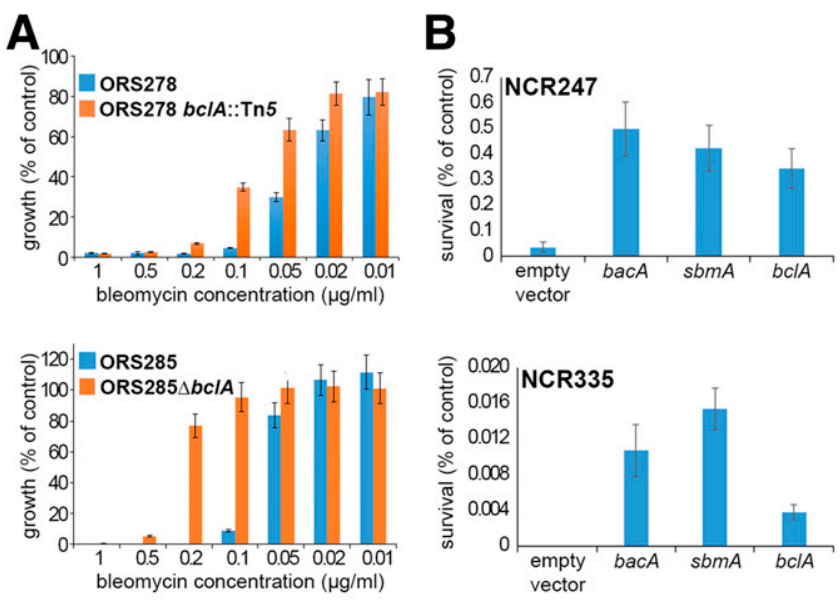

ORS285 $\triangle$ bcIA PMG103
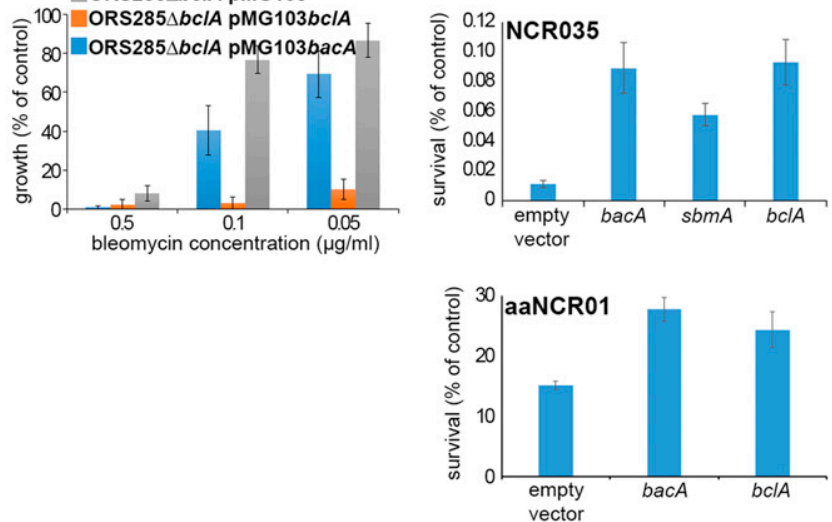

Fig. 6. Gene $b c l A$ confers sensitivity to the antibiotic bleomycin and resistance to antimicrobial nodule-specific cysteine-rich (NCR) peptides. A, Bleomycin sensitivity in Bradyrhizobium sp. strains ORS278 and ORS285, their $b c l A$ mutant derivatives, and the complemented ORS285 mutant carrying the $b c l A$ or $b a c A$ genes on plasmid pMG103. Bleomycin was applied at the indicated concentrations and growth was determined after $72 \mathrm{~h}$ of incubation by optical density measurement at $600 \mathrm{~nm}$ with a plate reader. B, Sinorhizobium meliloti strain Sm1021 $\Delta$ bacA derivatives expressing no bacA-related gene (empty vector), the Sm1021 bacA gene, the Escherichia coli BW25113 sbmA gene, or the ORS285 bclA gene were incubated with NCR247, NCR335 or NCR035 at $50 \mu \mathrm{g} / \mathrm{ml}$; with $7.5 \mu \mathrm{M}$ aaNCR01; or with solvent only (control) and the surviving bacteria were counted and expressed as percentage from the control treatment. Error bars in all panels are standard deviations. to withstand the NCR peptides within the symbiotic cells of Medicago nodules and to differentiate into elongated and polyploid bacteroids (Haag et al. 2011). Here, we provide multiple lines of evidence that the Bradyrhizobium symbionts of Aeschynomene plants use the homologous protein $\mathrm{BclA}$ for the same purpose. We show that the $b c l A$ mutant of Bradyrhizobium sp. strains ORS285 and ORS278 does not differentiate or hardly differentiates (no or little cell enlargement and DNA amplification) within the symbiotic cells of Aeschynomene nodules. Furthermore, we demonstrate that the $b c l A$ gene partially complements the $S$. meliloti bacA mutation in symbiosis with Medicago plants as well as in free-living growth, conferring resistance to the antimicrobial peptides bleomycin and Bac7 that have intracellular targets and whose uptake by E. coli or $S$. meliloti is dependent on an SbmA_BacA type of transporter. Finally, we show that BclA, as well as BacA of $S$. meliloti, promotes the uptake of NCR peptides and confers protection against them.

Although BacA of S. meliloti and BclA of Bradyrhizobium spp. have a key role in symbiosis, BacA-related proteins do not have
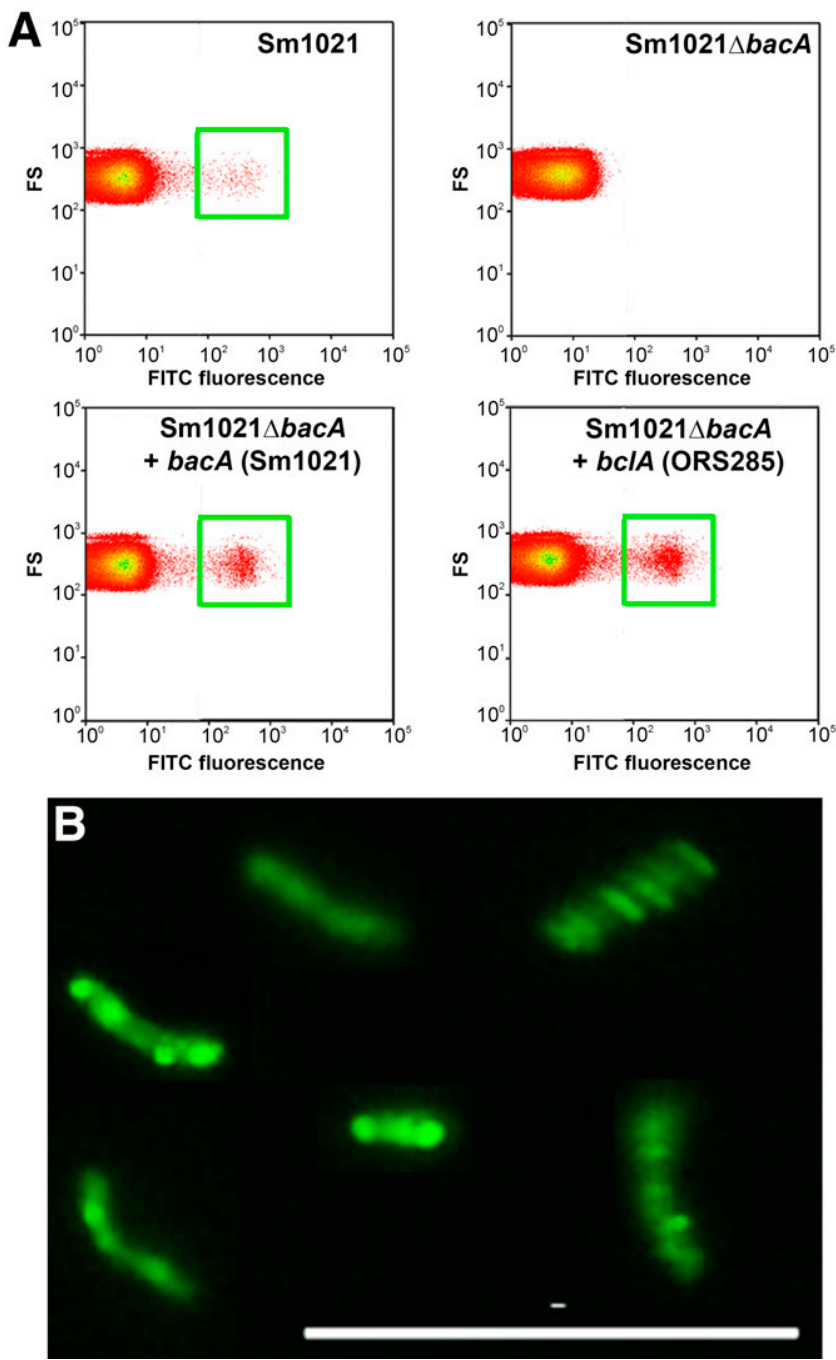

Fig. 7. Uptake of fluorescein isothiocyanate (FITC)-NCR247 mediated by the BacA and BclA transporters. A, FITC-NCR247 uptake by Sinorhizobium meliloti strain Sm1021, Sm1021 $\triangle b a c A$, and derivatives expressing the Sm1021 bacA gene or the ORS285 bclA gene was measured by flow cytometry in the presence of trypan blue to quench extracellular fluorescence. FITC-positive cells are marked with a green box. B, Intracellular accumulation of NCR247 revealed by epifluorescence microscopy of FITC-NCR247-treated Sm1021 $\Delta$ bacApRF711bacA cells and sorted as FITC positive by the flow cytometer-cell sorter. Scale bar $=10 \mu \mathrm{m}$. 
an exclusive symbiotic function because they are present in nonsymbiotic bacteria (e.g., E. coli or Mycobacterium spp.) or in rhizobia in which they do not have a role in symbiosis, in the interaction with legumes that do not produce NCR peptides (Haag et al. 2011). The "household" role of these transporters is hitherto unknown but, apparently, their capacity to import peptides has been co-opted at least twice among the rhizobia to respond to or provide protection against peptides produced by the host cell. It will be interesting in the future to determine whether BacArelated proteins have a role in other symbiotic interactions as well.

The $S$. meliloti bacA mutant dies rapidly after its release from the infection threads in Medicago nodules as a consequence of its hypersensitivity to the NCR peptides and is then lysed (Haag et al. 2011). This results in nodules in which the symbiotic cells filled with bacterial cells rapidly disappear. Here, we found that the Bradyrhizobium bclA mutant bacteria have a much higher capacity to persist within the symbiotic cells of Aeschynomene nodules than the $S$. meliloti bacA mutant in Medicago symbiotic cells. One possibility could be that the Aeschynomene symbiotic cells produce a much less aggressive arsenal of peptides than the Medicago symbiotic cells. In agreement with this, none of the tested Aeschynomene peptides displayed antimicrobial activity against Bradyrhizobium bacteria and only one was active on S. meliloti (Czernic et al. 2015). Alternatively, Bradyrhizobium bacteria could have better capacity than $S$. meliloti to maintain cell integrity after exposure to membrane-disrupting molecules such as the NCR peptides. Such a capacity could be related to the unusual membrane composition of these bacteria, which is extremely rich in hopanoids (Silipo et al. 2014). Hopanoids are pentacyclic triterpenoids displaying structural similarity to eukaryotic sterols. Hopanoids stabilize the bacterial membrane, controlling its fluidity, permeability and integrity under stress conditions.

Even if the survival of the bclA mutant bacteria is not immediately affected after their release in the symbiotic cells, it is clearly affected at later time points in the A. indica and $A$. evenia symbiotic cells but not in the $A$. afraspera symbiotic cells, suggesting that the former may produce a spectrum of peptides which are more virulent to the bacteria than those of the latter. This difference translates to a more severely reduced nitrogen fixation capability of the $b c l A$ mutant bacteroids in A. indica or A. evenia nodules compared with A. afraspera. The different NCR spectrum could also be the basis of the $\mathrm{S}$-morphotype versus E-morphotype bacteroids formed by A. indica and A. evenia compared with A. afraspera.

The bclA gene of Bradyrhizobium sp. strain ORS285 partially complements the bacA mutation of $S$. meliloti in symbiosis with Medicago bacteria. The complementation is obvious by the production of the late developmental marker leghemoglobin, which is never produced in the mutant nodules, and by the elongated bacteroids, which seem alive because they are not stained with the PI marker for bacterial death. Nevertheless, these nodules remain smaller than wild-type nodules, they do not accumulate leghemoglobin to the same extent, they senesce earlier than normal (as indicated by the PI staining of the bacteroids when symbiotic cells grow older), and the nodules do not fix nitrogen or support plant growth. This partial complementation resembles the complementation level obtained by the Mycobacterium tuberculosis bacA gene (Arnold et al. 2013) and could result from a different spectrum of peptides that can be transported or different transport kinetics by the endogenous BacA of $S$. meliloti and the Bradyrhizobium BclA or M. tuberculosis $\mathrm{BacA}$. In this respect, it is interesting to note that, although BacA, SbmA, and BclA share an SbmA_BacA transmembrane domain, they have an otherwise different architecture and transport mechanism: SbmA and BacA lack an ATPase domain and transport is driven by the membrane electrochemical gradient (Runti et al. 2013) while BclA and Mycobacterium BacA have a C-terminal cytosolic ATPase domain that provides the energy for transport (Arnold et al. 2013). Medicago plants produce NCR peptides in different waves, and the large majority of peptides are produced at later stages (Guefrachi et al. 2014). Possibly, BclA or M. tuberculosis BacA are sufficient to support the early waves of NCR production but become limited when the later waves are activated, ultimately resulting in the death of the bacteroids, even after their differentiation.

Even though Bradyrhizobium BclA can partially replace BacA function in S. meliloti, we found that the inverse was not the case. Possibly, BacA requires additional but hitherto unknown factors for functioning and those factors might be absent in Bradyrhizobium spp. Alternatively, BacA and BclA have not entirely overlapping substrate specificities and BacA might be unable to transport critical NCR peptides produced by Aeschynomene plants.

BacA-related transporters are not only critical in rhizobia for chronic intracellular infections of legume hosts which produce NCR peptides in the symbiotic cells. They also contribute to the pathogenesis and chronic infection in pathogens, and they most likely do this by protecting the bacteria against the host antimicrobial peptides (Arnold et al. 2013; Domenech et al. 2009; Haag et al. 2011; LeVier et al. 2000). However, how the transporters function mechanistically and contribute to resistance against antimicrobial peptides requires further investigation. An attractive hypothesis is that the internalization of peptides would move them away from the bacterial membrane which is the main target of many antimicrobial peptides, including the toxic NCR peptides, and at the same time bring them in proximity to intracellular targets (for example, bacterial cell cycle regulators leading to polyploidization and enlargement of the bacteria) or destine them for degradation. In the case of peptides such as Bac7 or bleomycin, the transporter would be a Trojan horse for the bacterial cell, bringing the enemy inside its walls, within reach of its intracellular targets.

\section{MATERIALS AND METHODS}

\section{Bacterial strains and growth conditions.}

Bradyrhizobium spp. strains were grown in yeast mannitol (YM) (Giraud et al. 2000) or buffered nodulation medium for bacteria (BNM-B) (Renier et al. 2011), E. coli in Luria-Bertani (LB) or Mueller-Hinton (MH) medium, and S. meliloti strains in LB medium. All bacterial strains used in this study are listed in Supplementary Table S2. Antibiotics for strain and plasmid selection were used at the following concentrations: streptomycin (Sm), $500 \mu \mathrm{g} / \mathrm{ml}$; spectinomycin (Sp), $100 \mu \mathrm{g} / \mathrm{ml}$; chloramphenicol $(\mathrm{Cm}), 12.5 \mu \mathrm{g} / \mathrm{ml}$; gentamycin $(\mathrm{Gm}), 15$ or $50 \mu \mathrm{g} / \mathrm{ml}$; carbenicilin $(\mathrm{Cb}), 50 \mu \mathrm{g} / \mathrm{ml}$; tetracycline (Tc), $10 \mu \mathrm{g} / \mathrm{ml}$; kanamycin $(\mathrm{Km}), 50$ or $200 \mu \mathrm{g} / \mathrm{ml}$; neomycin $(\mathrm{Nm}), 120 \mu \mathrm{g} / \mathrm{ml}$; and nalidixic acid (Nal), $25 \mu \mathrm{g} / \mathrm{ml}$.

\section{Construction of bacterial mutants and complemented strains.}

Standard molecular biology techniques were used for all cloning work. For the construction of Bradyrhizobium sp. strain ORS285 mutants in the SbmA_BacA domain ABC transporter genes BRAO285v1_250005 (GenBank accession number KR905749) and BRAO285v1_950010 (GenBank accession number KR905750), 400- to 600-bp fragments were amplified by polymerase chain reaction (PCR) using the primers CATGATCTCGAGGTCATC CCGCTGTTGTTGT (250005_XhoI_for), TTATCGACTAGTG ATGCGGTCCTTGAGATGAT (250005_SpeI_rev), CATGATC TCGAGGATCGAGAACGACCGCTATG (950010_XhoI_for), and TTATCGACTAGTGGTATGTGAGACCAGCGTCA (950010_SpeI_rev). PCR products were cloned into the plasmid pVO155nptIIgfp (plasmid pVO155, carrying a constitutively expressed green fluorescent protein $[g f p]$ gene) (Oke and Long 
1999), which does not replicate in S. meliloti. The resulting pVO155 derivatives were verified by PCR and sequencing and subsequently introduced in Bradyrhizobium sp. strain ORS285 by triparental mating using the helper strain HB101.pRK600 (Finan et al. 1986). ORS285 clones with the plasmid integrated in the genome were selected on YM medium with $\mathrm{Gm}(15 \mu \mathrm{g} / \mathrm{ml})$ for counter-selection of the E. coli and $\mathrm{Km}$ for selection of the plasmid. The integration of the plasmids in the target genes by homologous recombination was verified by PCR.

A deletion mutant of the $b c l A$ gene in strain ORS285 (BRAO285v1_1320006; GenBank accession number KR905748) was obtained as follows. The 600-bp upstream and downstream regions of the $b c l A$ open reading frames were obtained by PCR using primers GATAGAAAGCTTAGACCGTGACCTGATAC AGGAAGATG (up_HindIII_for) and CCTGGATGCGGGAT CCAGAGAGGCTGCTCCTGAAAAAAGG (up_BamHI_rev) for the upstream region and CAGCCTCTCTGGATCCCGC ATCCAGGCTGGGCGGCGCCTC (down_BamHI_for) and GATAGAACTAGTGTCGTTTTTTGTCCAGAGCCTGATG (down_SpeI_rev) for the downstream region. The two regions were merged by sewing PCR and cloned in the pGEM-Teasy vector (Promega Corp.). The Gm resistance cassette from plasmid p34S-Gm (Dennis and Zylstra 1998) was cloned in between the upstream and downstream regions. The fragments of the upstream region-Gm cassette-downstream region were subsequently transferred into the vector $\mathrm{pK} 18 \mathrm{mob}-\mathrm{sacB}$ (Schäfer et al. 1994). This plasmid cannot replicate in Bradyrhizobium spp. and carries the $s a c B$ gene that induces bacterial death in the presence of sucrose. The pK18mob-sacB derivatives were introduced in the respective Bradyrhizobium spp. strains by triparental mating, as above. Single recombinant clones were obtained by antibiotic selection and verified by PCR. Double recombinant clones were then obtained by growth on sucrose and $\mathrm{Gm}(50 \mu \mathrm{g} / \mathrm{ml})$. Candidate clones were verified for the loss of $\mathrm{Km}$ resistance from the $\mathrm{pK} 18 \mathrm{mob}-\mathrm{sacB}$ plasmid, and the replacement of the $b c l A$ gene by the Gm cassette was verified by PCR.

For complementation experiments of bacA or $\operatorname{sbmA}$ mutations in S. meliloti Sm1021 or E. coli BW25113, the genes of interest were introduced into the broad host range vector pRF771 under the control of the trp promoter (Wells and Long 2002). The plasmid pRF771bacA ${ }^{\text {Sm1021 }}$ (Haag et al. 2011) carries the $S$. meliloti bacA gene. The sbmA gene from $E$. coli strain BW25113 and the bclA gene from Bradyrhizobium sp. strain ORS285 were obtained by PCR using the following primers: TTATCGTCTAGATTTTCAGGAGCAGCCTCTCT (bclA_XbaI_for) and CATGATGGATCCCCAGCCTGGATGC GCTACTCG (bclA_BamHI_rev) for the bclA gene and TTAT CGTCTAGAACGATAAGAAGTTAGCAGGAGTGC (sbmA $X b a \mathrm{I}$ for) and CATGATGGATCCACTTCTCCTTTTTAGCT CAAGG (sbmA_BamHI_rev) for the $s b m A$ gene. PCR products were cloned in the multicloning site of pRF771. The plasmids were introduced in the $S$. meliloti mutant Sm1021 $\Delta$ bacA by triparental conjugation and in the E. coli mutant BW25113 $\Delta$ sbmA by electroporation.

For complementation experiments in the ORS285 background, the $b c l A$ and $b a c A$ genes were transferred from the pRF771 plasmids as EcoRI-BamHI fragments into the plasmid pMG103 (Inui et al. 2000), which stably replicates in Bradyrhizobium sp. strain ORS285 (Bonaldi et al. 2010a). These DNA fragments contain the trp promoter upstream of the $b c l A$ or bacA gene. The constructs were introduced in Bradyrhizobium bacteria by electroporation.

\section{Bacterial growth and nitrogen fixation assays.}

Bradyrhizobium sp. strain ORS285 and ORS285 $\Delta b c l A$ were grown in YM medium and washed, and the pellet was resuspended in rich YM medium or in defined BNM-B medium. The bacterial suspensions were diluted to an optical density at $600 \mathrm{~nm}$ $\left(\mathrm{OD}_{600}\right)=0.01$ and distributed in microtiter plates. Bacterial growth $\left(\mathrm{OD}_{600}\right)$ was monitored in a plate reader at different times.

For free-living nitrogen fixation activity measurements with the acetylene reduction assay, bacterial precultures in YM medium were pelleted by centrifugation and resuspended in BNM-B medium without nitrogen source. Cell suspensions $(200 \mu \mathrm{l})$ at $\mathrm{OD}_{600}=1.5$ were mixed with $7 \mathrm{ml}$ of melted $1 \%$ agar medium and added to $10-\mathrm{ml}$, gas-tight glass vials, and $0.8 \mathrm{ml}$ of $100 \%$ acetylene was injected. The cultures were incubated at $28^{\circ} \mathrm{C}$ in the dark for 7 days. Gas samples $(200 \mu \mathrm{l})$ were analyzed for the amount of ethylene formed by gas chromatography on a 7820A GC system (Agilent Technologies).

\section{Bleomycin, Bac7, and NCR sensitivity assays.}

E. coli, S. meliloti, and Bradyrhizobium spp. strains were grown in liquid $\mathrm{MH}, \mathrm{LB}$, and $\mathrm{YM}$ medium at 37,30 , or $30^{\circ} \mathrm{C}$, respectively, in the presence of appropriate antibiotics for plasmid selection. Within an experiment, cultures were repeatedly diluted until all strains grew at the same OD. Sensitivity tests were performed on cultures that had not grown over $\mathrm{OD}_{600}=0.5$. All experiments have been performed at least in triplicate with identical results. A representative example is shown in the figures.

For bleomycin sensitivity tests, bacterial suspensions were diluted with fresh medium until $\mathrm{OD}_{600}=0.005$ for $E$. coli and S. meliloti or $\mathrm{OD}_{600}=0.01$ for Bradyrhizobium spp. strains. The bacterial suspensions were distributed in microtiter plates, $100 \mu \mathrm{l}$ per well, and bleomycin stock solution was added to reach the desired final concentration. The plates were incubated with agitation $(200 \mathrm{rpm})$ at $30^{\circ} \mathrm{C}$ for Bradyrhizobium spp. and $S$. meliloti or $37^{\circ} \mathrm{C}$ for E. coli. Growth was determined after $24 \mathrm{~h}$ for E. coli, $48 \mathrm{~h}$ for $S$. meliloti, or $72 \mathrm{~h}$ for Bradyrhizobium spp. by measurement of the $\mathrm{OD}_{600}$ with a plate reader.

For Bac7 sensitivity tests, $S$. meliloti or E. coli suspensions were diluted to $\mathrm{OD}_{600}=0.005$ in $\mathrm{LB}$ medium, and $100-\mu \mathrm{l}$ suspensions were incubated in the presence of 0,2 , or $4 \mu \mathrm{M}$ Bac 7 peptide at 30 or $37^{\circ} \mathrm{C}$ for 4 or $3 \mathrm{~h}$ and $6 \mathrm{~h}$, respectively. Ten-fold dilution series were then spotted on agar plates and the $\mathrm{CFU}$ were determined after 72 or $24 \mathrm{~h}$ of growth at 30 or $37^{\circ} \mathrm{C}$.

NCR sensitivity assays were performed as before (Haag et al. 2011) or with modifications. S. meliloti strains were resuspended in $10 \mathrm{mM}$ sodium phosphate buffer, $\mathrm{pH}$ 7.0. The suspensions $(100 \mu \mathrm{l})$ were incubated with the indicated NCR peptides at a final concentration of $50 \mu \mathrm{g} / \mathrm{ml}$ for $4 \mathrm{~h}$ at $30^{\circ} \mathrm{C}$. Ten-fold dilution series were then spotted on agar plates and the $\mathrm{CFU}$ were determined after $72 \mathrm{~h}$ at $30^{\circ} \mathrm{C}$. The Aeschynomene aaNCR01 peptide (accession number L0008932) (Czernic et al. 2015) was resuspended in $50 \mathrm{mM}$ phosphate buffer, $\mathrm{pH} 4.5$, at $1.5 \mathrm{mM}$ for the stock solutions. For the tests with these peptides, bacterial cultures were harvested at the exponential growth phase $\left(\mathrm{OD}_{600}<0.5\right)$ and resuspended at $\mathrm{OD}_{600}=0.1$ in $\mathrm{YM}$ media adjusted to $\mathrm{pH} 4.6$ by adding $0.2 \mathrm{M}$ succinic acid at a ratio of 1/125. Peptides were added to the desired final concentrations.

\section{Single-cell NCR peptide uptake assay and flow cytometry.}

Strains were grown in LB medium to midlog phase, below $\mathrm{OD}_{600}=0.5$, washed, and resuspended at $\mathrm{OD}_{600}=0.05$ in $50 \mathrm{mM}$ phosphate buffer, $\mathrm{pH}$ 7.0. Then, $1 \mu \mathrm{M}$ FITC-NCR247 (Farkas et al. 2014) or free FITC was added and cells were incubated for $1 \mathrm{~h}$ at $30^{\circ} \mathrm{C}$. Cells were washed and resuspended in $50 \mathrm{mM}$ phosphate buffer, $\mathrm{pH} 7.0$, supplemented with trypan blue at $1 \mathrm{mg} / \mathrm{ml}$ used as an extracellular fluorescence quencher (Mattiuzzo et al. 2007). FITC uptake was assayed using a MoFlo ASTRIOS flow cytometer (Beckman Coulter) with a 488-nm laser, and fluorescence was recorded through a 526/552-nm band pass filter. More than 200,000 events were acquired and analyzed with Summit 6.2 software (Beckman Coulter). To further 
confirm the internalization of FITC-NCR247, FITC-positive cells were sorted and imaged with an Eclipse 80i microscope (Nikon) equipped with an FITC-appropriate filter set.

\section{Plant growth and nodulation.}

A. indica, A. evenia, or $A$. afraspera seed were surface sterilized and germinated overnight at $34^{\circ} \mathrm{C}$ in the dark. One-dayold seedlings were transferred to test tubes containing liquid BNM (Ehrhardt et al. 1992). Seedlings were grown at $28^{\circ} \mathrm{C}$ with a 16-h light regime and $70 \%$ humidity. Seven days after germination, each seedling was inoculated with $2 \mathrm{ml}$ of a bacterial suspension adjusted to an $\mathrm{OD}_{600}=0.2$.

Medicago sativa (alfalfa) seed were surface sterilized and germinated overnight at room temperature. Seedlings were planted in pots containing a mixture of perlite and sand (3:1, vol/vol) and grown at $24^{\circ} \mathrm{C}$ with a $16-\mathrm{h}$ light regime and $40 \%$ humidity. Threeday-old plantlets were inoculated with a bacterial suspension as described above. Plants were watered with BNM medium.

Acetylene reduction assays were performed on plants 2 weeks after inoculation. Single whole plants were placed into 20 -ml gas-tight glass vials and $200 \mu \mathrm{l}$ of acetylene was added. Gas samples $(200 \mu \mathrm{l})$ were withdrawn after $3 \mathrm{~h}$ of incubation at $28^{\circ} \mathrm{C}$ and ethylene was measured by gas chromatography on a 7820A GC system (Agilent Technologies). The assay was done with a minimum of five biological replicates.

\section{Microscopy.}

For histological analysis, nodules were fixed in $1 \%$ glutaraldehyde and $4 \%$ formaldehyde in $0.1 \mathrm{M}$ phosphate buffer, $\mathrm{pH} 7.2$, then washed, dehydrated, and embedded in Technovit 7100 resin (KulzerHistoTechnik). Sections $(5 \mu \mathrm{m}$ each) were cut with a Leica RM2155 microtome, stained with $0.005 \%$ toluidine blue, and then mounted with DPX (VWR International Ltd). Bright field images were acquired with an Eclipse 80i microscope (Nikon).

For live-dead (Haag et al. 2011) and DND-99 (Pierre et al. 2013) staining, nodules were harvested, embedded with $6 \%$ agarose, and then freshly sectioned with a Leica VT1200S vibratome (Leica Microsystems $\mathrm{GmbH}$ ) into $70-\mu \mathrm{m}$ tissue slices. Slices were incubated for $20 \mathrm{~min}$ in Live-Dead BacLight (Molecular Probes) staining solution or in $5 \mu \mathrm{M}$ DND-99 LysoTracker Red (Molecular Probes) in $50 \mathrm{mM}$ Tris buffer, $\mathrm{pH}$ 7.0. Sections were washed of any excess of dye and observed using a Leica TCS SP8x confocal microscope.

\section{Bacteroid purification and flow cytometry analysis.}

Bacteroids or cultured bacteria were purified as described (Mergaert et al. 2006). Bacteria were then fixed by heat treatment $\left(70^{\circ} \mathrm{C}, 10 \mathrm{~min}\right)$ and stained by DAPI at $20 \mu \mathrm{g} / \mathrm{ml}$ before flow cytometry analysis using a MoFlo ASTRIOS flow cytometer (Beckman Coulter). Bacterial size was estimated by the FS and the bacterial DNA content was assessed by the DAPI fluorescence with a 355-nm laser line. Each single event was recorded and analyzed with the Summit 6.2 software (Beckman Coulter). Experiments have been performed in at least three biological replicates.

\section{ACKNOWLEDGMENTS}

We thank M. Scocchi and M. Mardirossian (University of Trieste, Italy) for providing the Bac7 peptide. I. Guefrachi was supported by a $\mathrm{Ph}$.D. fellowship from the Tunisian Ministry of Higher Education and Scientific Research, the International Relations Office of Université Paris Sud 11, and the Agence Universitaire de la Francophonie (AUF). This work has benefitted from the facilities and expertise of the Imagif Cell Biology Unit of the Gif campus, which is supported by the "Infrastructures en Biologie Santé et Agronomie" (IBiSA), the "Agence Nationale de la Recherche" (ANR) under Investments for the Future programs "France-BioImaging infrastructure" (ANR-10-INSB-04-01), "Saclay Plant Sciences" (ANR-10LABX-0040-SPS), and also the Conseil Général de l'Essonne. This work was funded by the France-Tunisia "Comité Mixte de Coopération Universitaire" (CMCU), project 14G0817 and by the ANR, grant "BugsInACell" number ANR-13-BSV7-0013.

\section{LITERATURE CITED}

Arnold, M. F., Haag, A. F., Capewell, S., Boshoff, H. I., James, E. K., McDonald, R., Mair, I., Mitchell, A. M., Kerscher, B., Mitchell, T. J., Mergaert, P., Barry, C. E., 3rd, Scocchi, M., Zanda, M., Campopiano, D. J., and Ferguson, G. P. 2013. Partial complementation of Sinorhizobium meliloti bacA mutant phenotypes by the Mycobacterium tuberculosis BacA protein. J. Bacteriol. 195:389-398.

Bonaldi, K., Gargani, D., Prin, Y., Fardoux, J., Gully, D., Nouwen, N., Goormachtig, S., and Giraud, E. 2011. Nodulation of Aeschynomene afraspera and $A$. indica by photosynthetic Bradyrhizobium Sp. strain ORS285: The nod-dependent versus the nod-independent symbiotic interaction. Mol. Plant-Microbe Interact. 24:1359-1371.

Bonaldi, K., Gherbi, H., Franche, C., Bastien, G., Fardoux, J., Barker, D., Giraud, E., and Cartieaux, F. 2010a. The Nod factor-independent symbiotic signaling pathway: Development of Agrobacterium rhizogenes-mediated transformation for the legume Aeschynomene indica. Mol. Plant-Microbe Interact. 23:1537-1544.

Bonaldi, K., Gourion, B., Fardoux, J., Hannibal, L., Cartieaux, F., Boursot, M., Vallenet, D., Chaintreuil, C., Prin, Y., Nouwen, N., and Giraud, E. 2010b. Large-scale transposon mutagenesis of photosynthetic Bradyrhizobium sp. strain ORS278 reveals new genetic loci putatively important for nod-independent symbiosis with Aeschynomene indica. Mol. PlantMicrobe Interact. 23:760-770.

Carro, L., Pujic, P., Alloisio, N., Fournier, P., Boubakri, H., Hay, A. E., Poly, F., François, P., Hocher, V., Mergaert, P., Balmand, S., Rey, M., Heddi, A., and Normand, P. 2015. Alnus peptides modify membrane porosity and induce the release of nitrogen-rich metabolites from nitrogen-fixing Frankia. ISME J. 9:1723-1733.

Czernic, P., Gully, D., Cartieaux, F., Moulin, L., Guefrachi, I., Patrel, D., Pierre, O., Fardoux, J., Chaintreuil, C., Nguyen, P., Gressent, F., Da Silva, C., Poulain, J., Wincker, P., Rofidal, V., Hem, S., Barrière, Q., Arrighi, J.-F., Mergaert, P., and Giraud, E. 2015. Convergent evolution of endosymbiont differentiation in Dalbergoid and IRLC legumes mediated by nodule-specific cysteine-rich peptides. Online publication. Plant Physiol. doi:10.1104/pp.15.00584

Demina, I. V., Persson, T., Santos, P., Plaszczyca, M., and Pawlowski, K. 2013. Comparison of the nodule vs. root transcriptome of the actinorhizal plant Datisca glomerata: Actinorhizal nodules contain a specific class of defensins. PLoS One 8:e72442.

Dennis, J. J., and Zylstra, G. J. 1998. Plasposons: Modular self-cloning minitransposon derivatives for rapid genetic analysis of gram-negative bacterial genomes. Appl. Environ. Microbiol. 64:2710-2715.

Domenech, P., Kobayashi, H., LeVier, K., Walker, G. C., and Barry, C. E., 3rd. 2009. BacA, an ABC transporter involved in maintenance of chronic murine infections with Mycobacterium tuberculosis. J. Bacteriol. 191:477-485.

Ehrhardt, D. W., Atkinson, E. M., and Long, S. R. 1992. Depolarization of alfalfa root hair membrane potential by Rhizobium meliloti Nod factors Science 256:998-1000.

Farkas, A., Maróti, G., Durgö, H., Györgypál, Z., Lima, R. M., Medzihradszky, K. F., Kereszt, A., Mergaert, P., and Kondorosi, É. 2014. Medicago truncatula symbiotic peptide NCR247 contributes to bacteroid differentiation through multiple mechanisms. Proc. Natl. Acad. Sci. U.S.A. 111:5183-5188.

Finan, T. M., Kunkel, B., De Vos, G. F., and Signer, E. R. 1986. Second symbiotic megaplasmid in Rhizobium meliloti carrying exopolysaccharide and thiamine synthesis genes. J. Bacteriol. 167:66-72.

Fraune, S., Augustin, R., Anton-Erxleben, F., Wittlieb, J., Gelhaus, C., Klimovich, V. B., Samoilovich, M. P., and Bosch, T. C. G. 2010. In an early branching metazoan, bacterial colonization of the embryo is controlled by maternal antimicrobial peptides. Proc. Natl. Acad. Sci. U.S.A. 107:18067-18072.

Futahashi, R., Tanaka, K., Tanahashi, M., Nikoh, N., Kikuchi, Y., Lee, B. L., and Fukatsu, T. 2013. Gene expression in gut symbiotic organ of stinkbug affected by extracellular bacterial symbiont. PLoS One 8:e64557.

Ghosal, A., Vitali, A., Stach, J. E., and Nielsen, P. E. 2013. Role of SbmA in the uptake of peptide nucleic acid (PNA)-peptide conjugates in E. coli. ACS Chem. Biol. 8:360-367.

Giraud, E., Hannibal, L., Fardoux, J., Verméglio, A., and Dreyfus, B. 2000 Effect of Bradyrhizobium photosynthesis on stem nodulation of Aeschynomene sensitiva. Proc. Natl. Acad. Sci. U.S.A. 97:14795-14800 
Glazebrook, J., Ichige, A., and Walker, G. C. 1993. A Rhizobium meliloti homolog of the Escherichia coli peptide-antibiotic transport protein SbmA is essential for bacteroid development. Genes Dev. 7:1485-1497.

Guefrachi, I., Nagymihaly, M., Pislariu, C. I., Van de Velde, W., Ratet, P., Mars, M., Udvardi, M. K., Kondorosi, E., Mergaert, P., and Alunni, B. 2014. Extreme specificity of NCR gene expression in Medicago truncatula. BMC Genomics 15:712.

Haag, A. F., Baloban, M., Sani, M., Kerscher, B., Pierre, O., Farkas, A., Longhi, R., Boncompagni, E., Hérouart, D., Dall'angelo, S., Kondorosi, E., Zanda, M., Mergaert, P., and Ferguson, G. P. 2011. Protection of Sinorhizobium against host cysteine-rich antimicrobial peptides is critical for symbiosis. PLoS Biol. 9:e1001169.

Hocher, V., Alloisio, N., Auguy, F., Fournier, P., Doumas, P., Pujic, P., Gherbi, H., Queiroux, C., Da Silva, C., Wincker, P., Normand, P., and Bogusz, D. 2011. Transcriptomics of actinorhizal symbioses reveals homologs of the whole common symbiotic signaling cascade. Plant Physiol. 156:700-711.

Ichige, A., and Walker, G. C. 1997. Genetic analysis of the Rhizobium meliloti bacA gene: Functional interchangeability with the Escherichia coli sbmA gene and phenotypes of mutants. J. Bacteriol. 179:209-216.

Inui, M., Roh, J. H., Zahn, K., and Yukawa, H. 2000. Sequence analysis of the cryptic plasmid pMG101 from Rhodopseudomonas palustris and construction of stable cloning vectors. Appl. Environ. Microbiol. 66: 54-63.

Kondorosi, E., Mergaert, P., and Kereszt, A. 2013. A paradigm for endosymbiotic life: Cell differentiation of Rhizobium bacteria provoked by host plant factors. Annu. Rev. Microbiol. 67:611-628.

LeVier, K., Phillips, R. W., Grippe, V. K., Roop, R. M., 2nd, and Walker, G. C. 2000. Similar requirements of a plant symbiont and a mammalian pathogen for prolonged intracellular survival. Science 287:2492-2493.

LeVier, K., and Walker, G. C. 2001. Genetic analysis of the Sinorhizobium meliloti BacA protein: Differential effects of mutations on phenotypes. J. Bacteriol. 183:6444-6453.

Login, F. H., Balmand, S., Vallier, A., Vincent-Monégat, C., Vigneron, A., Weiss-Gayet, M., Rochat, D., and Heddi, A. 2011. Antimicrobial peptides keep insect endosymbionts under control. Science 334:362-365.

Mardirossian, M., Grzela, R., Giglione, C., Meinnel, T., Gennaro, R., Mergaert, P., and Scocchi, M. 2014. The host antimicrobial peptide Bac71-35 binds to bacterial ribosomal proteins and inhibits protein synthesis. Chem. Biol. 21:1639-1647.

Marlow, V. L., Haag, A. F., Kobayashi, H., Fletcher, V., Scocchi, M., Walker, G. C., and Ferguson, G. P. 2009. Essential role for the BacA protein in the uptake of a truncated eukaryotic peptide in Sinorhizobium meliloti. J. Bacteriol. 191:1519-1527.

Masson-Boivin, C., Giraud, E., Perret, X., and Batut, J. 2009. Establishing nitrogen-fixing symbiosis with legumes: How many rhizobium recipes? Trends Microbiol. 17:458-466.

Mattiuzzo, M., Bandiera, A., Gennaro, R., Benincasa, M., Pacor, S., Antcheva, N., and Scocchi, M. 2007. Role of the Escherichia coli SbmA in the antimicrobial activity of proline-rich peptides. Mol. Microbiol. 66: 151-163.

Mergaert, P., Nikovics, K., Kelemen, Z., Maunoury, N., Vaubert, D., Kondorosi, A., and Kondorosi, E. 2003. A novel family in Medicago truncatula consisting of more than 300 nodule-specific genes coding for small, secreted polypeptides with conserved cysteine motifs. Plant Physiol. 132:161-173.

Mergaert, P., Uchiumi, T., Alunni, B., Evanno, G., Cheron, A., Catrice, O., Mausset, A. E., Barloy-Hubler, F., Galibert, F., Kondorosi, A., and Kondorosi, E. 2006. Eukaryotic control on bacterial cell cycle and differentiation in the Rhizobium-legume symbiosis. Proc. Natl. Acad. Sci. U.S.A. 103:5230-5235.

Moran, N. A. 2006. Symbiosis. Curr. Biol. 16:R866-R871.

Narayanan, S., Modak, J. K., Ryan, C. S., Garcia-Bustos, J., Davies, J. K., and Roujeinikova, A. 2014. Mechanism of Escherichia coli resistance to Pyrrhocoricin. Antimicrob. Agents Chemother. 58:2754-2762.

Oke, V., and Long, S. R. 1999. Bacterial genes induced within the nodule during the Rhizobium-legume symbiosis. Mol. Microbiol. 32:837-849.

Oono, R., Schmitt, I., Sprent, J. I., and Denison, R. F. 2010. Multiple evolutionary origins of legume traits leading to extreme rhizobial differentiation. New Phytol. 187:508-520.

Penterman, J., Abo, R. P., De Nisco, N. J., Arnold, M. F. F., Longhi, R., Zanda, M., and Walker, G. C. 2014. Host plant peptides elicit a transcriptional response to control the Sinorhizobium meliloti cell cycle during symbiosis. Proc. Natl. Acad. Sci. U.S.A. 111:3561-3566.

Pierre, O., Engler, G., Hopkins, J., Brau, F., Boncompagni, E., and Hérouart, D. 2013. Peribacteroid space acidification: A marker of mature bacteroid functioning in Medicago truncatula nodules. Plant Cell Environ. 36:2059-2070.

Pini, F., Frage, B., Ferri, L., De Nisco, N. J., Mohapatra, S. S., Taddei, L., Fioravanti, A., Dewitte, F., Galardini, M., Brilli, M., Villeret, V., Bazzicalupo, M., Mengoni, A., Walker, G. C., Becker, A., and Biondi, E. G. 2013. The DivJ, CbrA and PleC system controls DivK phosphorylation and symbiosis in Sinorhizobium meliloti. Mol. Microbiol. 90:54-71.

Puckett, S. E., Reese, K. A., Mitev, G. M., Mullen, V., Johnson, R. C., Pomraning, K. R., Mellbye, B. L., Tilley, L. D., Iversen, P. L., Freitag, M., and Geller, B. L. 2012. Bacterial resistance to antisense peptide phosphorodiamidate morpholino oligomers. Antimicrob. Agents Chemother. 56:6147-6153.

Renier, A., Maillet, F., Fardoux, J., Poinsot, V., Giraud, E., and Nouwen, N. 2011. Photosynthetic Bradyrhizobium Sp. strain ORS285 synthesizes 2-O-methylfucosylated lipochitooligosaccharides for nod genedependent interaction with Aeschynomene plants. Mol. Plant-Microbe Interact. 24:1440-1447.

Runti, G., Lopez Ruiz, Mdel. C., Stoilova, T., Hussain, R., Jennions, M., Choudhury, H. G., Benincasa, M., Gennaro, R., Beis, K., and Scocchi, M. 2013. Functional characterization of SbmA, a bacterial inner membrane transporter required for importing the antimicrobial peptide Bac7(1-35). J. Bacteriol. 195:5343-5351.

Ryu, J. H., Kim, S. H., Lee, H. Y., Bai, J. Y., Nam, Y. D., Bae, J. W., Lee, D. G., Shin, S. C., Ha, E. M., and Lee, W. J. 2008. Innate immune homeostasis by the homeobox gene caudal and commensal-gut mutualism in Drosophila. Science 319:777-782.

Salzman, N. H., Hung, K., Haribhai, D., Chu, H., Karlsson-Sjöberg, J., Amir, E., Teggatz, P., Barman, M., Hayward, M., Eastwood, D., Stoel, M., Zhou, Y., Sodergren, E., Weinstock, G. M., Bevins, C. L., Williams, C. B., and Bos, N. A. 2010. Enteric defensins are essential regulators of intestinal microbial ecology. Nat. Immunol. 11:76-83.

Schäfer, A., Tauch, A., Jäger, W., Kalinowski, J., Thierbach, G., and Pühler, A. 1994. Small mobilizable multi-purpose cloning vectors derived from the Escherichia coli plasmids pK18 and pK19: Selection of defined deletions in the chromosome of Corynebacterium glutamicum. Gene 145:69-73.

Shigenobu, S., and Stern, D. L. 2012. Aphids evolved novel secreted proteins for symbiosis with bacterial endosymbiont. Proc. Biol. Sci. 280:20121952.

Silipo, A., Vitiello, G., Gully, D., Sturiale, L., Chaintreuil, C., Fardoux, J., Gargani, D., Lee, H. I., Kulkarni, G., Busset, N., Marchetti, R., Palmigiano, A., Moll, H., Engel, R., Lanzetta, R., Paduano, L., Parrilli, M., Chang, W. S., Holst, O., Newman, D. K., Garozzo, D., D’Errico, G., Giraud, E., and Molinaro, A. 2014. Covalently linked hopanoid-lipid A improves outer-membrane resistance of a Bradyrhizobium symbiont of legumes. Online publication. Nat. Commun. 5, Article number 5106. doi: $10.1038 /$ ncomms6106

Van de Velde, W., Zehirov, G., Szatmari, A., Debreczeny, M., Ishihara, H. Kevei, Z., Farkas, A., Mikulass, K., Nagy, A., Tiricz, H., SatiatJeunemaître, B., Alunni, B., Bourge, M., Kucho, K., Abe, M., Kereszt, A., Maroti, G., Uchiumi, T., Kondorosi, E., and Mergaert, P. 2010. Plant peptides govern terminal differentiation of bacteria in symbiosis. Science 327:1122-1126.

Wehmeier, S., Arnold, M. F. F., Marlow, V. L., Aouida, M., Myka, K. K., Fletcher, V., Benincasa, M., Scocchi, M., Ramotar, D., and Ferguson, G. P. 2010. Internalization of a thiazole-modified peptide in Sinorhizobium meliloti occurs by BacA-dependent and -independent mechanisms. Microbiology 156:2702-2713.

Wells, D. H., and Long, S. R. 2002. The Sinorhizobium meliloti stringent response affects multiple aspects of symbiosis. Mol. Microbiol. 43: 1115-1127.

Yorgey, P., Lee, J., Kördel, J., Vivas, E., Warner, P., Jebaratnam, D., and Kolter, R. 1994. Posttranslational modifications in microcin B17 define an additional class of DNA gyrase inhibitor. Proc. Natl. Acad. Sci. U.S.A. 91:4519-4523.

\section{AUTHOR-RECOMMENDED INTERNET RESOURCE}

Imagif Cell Biology Unit of the Gif campus: www.imagif.cnrs.fr 